\title{
Research on Ultrasonic Transducers to Accurately Determine Distances in a Coal Mine Conditions
}

\author{
Sławomir Bartoszek $^{1, *(\mathbb{D})}$, Krzysztof Stankiewicz ${ }^{1} \mathbb{D}$, Gabriel Kost ${ }^{2} \mathbb{D}$, Grzegorz Ćwikła ${ }^{2}$ (D) and Artur Dyczko ${ }^{3}$ \\ 1 KOMAG Institute of Mining Technology, Pszczyńska 37, 44-101 Gliwice, Poland; kstankiewicz@komag.eu \\ 2 Faculty of Mechanical Engineering, Silesian University of Technology, Konarskiego 18A, \\ 44-100 Gliwice, Poland; gabriel.kost@polsl.pl (G.K.); grzegorz.cwikla@polsl.pl (G.Ć.) \\ 3 Mineral and Energy Economy Research Institute of the Polish Academy of Sciences, J. Wybickiego 7a, \\ 31-261 Kraków, Poland; arturdyczko@min-pan.krakow.pl \\ * Correspondence: sbartoszek@komag.eu
}

Citation: Bartoszek, S.; Stankiewicz, K.; Kost, G.; Ćwikła, G.; Dyczko, A. Research on Ultrasonic Transducers to Accurately Determine Distances in a Coal Mine Conditions. Energies 2021, 14, 2532. https://doi.org/ $10.3390 /$ en14092532

Academic Editor:

Nikolaos Koukouzas

Received: 31 March 2021

Accepted: 22 April 2021

Published: 28 April 2021

Publisher's Note: MDPI stays neutral with regard to jurisdictional claims in published maps and institutional affiliations.

Copyright: (c) 2021 by the authors. Licensee MDPI, Basel, Switzerland. This article is an open access article distributed under the terms and conditions of the Creative Commons Attribution (CC BY) license (https:// creativecommons.org/licenses/by/ $4.0 /)$.
Abstract: Determining the location of objects, for example roadheader in a hard coal mine, is a task that should be automated in the conditions of state-of-the-art mining. Current solutions do not meet the user's expectations due to the lack of the possibility of automation, maladjustment to the environment of a hard coal mine or not meeting the legal requirements. The article describes the initial stage of work on an automatic system for determining the position of machines in difficult underground conditions, including the analysis of requirements and constraints, an overview of available solutions, technologies and algorithms, as a result of which devices were selected for further tests. To determine the location, it is necessary to take distance measurements with high accuracy, despite the disturbances resulting from the working environment. Ultrasonic devices were selected and then tested under various operating conditions, including different distances between the transmitter and receiver as well as different directions and intensities of air movement that could distort the measurement results. During tests, sufficient accuracy, as well as other parameters, of the ultrasonic transducers were confirmed, allowing for distance measurements in the required range, suitable for use in the real-time locating system (RTLS) being developed.

Keywords: ultrasonic transducers; distance measuring; indoor locating system; RTLS; coal mine; roadheader

\section{Introduction}

As in other industries, the implementation of state-of-the art technologies is as a priority in the coal mining industry. Ensuring the profitability of production, increase of competitiveness, improvement of work safety and reduce the environmental impact is the main objective. Modification of the method for the development of roadways, in terms of increasing the drilling rate and reducing the drilling cost, is considered to be one of the most important directions of research work enabling the achievement of the strategic mining goals. The necessity to perfect the drilling technique is also associated with deteriorating conditions accompanying this process. Deterioration of the physical and mechanical properties of rocks is influenced by the increasing depth of the mined coal seams [1]. The level of automation of the work related to roadways development is still low, part of the work is manual. The operator also controls the roadheader manually, relying mainly on his own senses and experience, therefore the mining is often ineffective. Tests were carried out to develop autonomous control systems for roadheaders [2,3]. As indicated by the authors of the research project, the positioning system, which allows the determination of the current position of the machine in the work is one of the necessary elements enabling the autonomous control of the roadheader. As practice shows, this problem has not been properly resolved so far. Typical positioning systems for roadheaders are mainly based on laser technology and are mostly used in tunnelling. Due to the 
regulations (ATEX Directive 2014/34/EU [4]) and the specificity of the mine environment, systems using devices such as theodolites, tachymeters or laser scanners have not been used in coal mines so far.

The ability to determine position was one of the features that allowed the development of civilization thanks to the ability to navigate in seas and in unknown terrain. Originally, the location was based on observing celestial bodies or other landmarks and determining the distance from them or angles between them. However, it is only recently that automatic determination of position is possible, thanks to systems known as RTLS (Real-time Locating Systems) [5]. RTLSs are currently widely used outdoors, where systems such as GPS (Global Positioning System), GLONASS (Global Navigation Satellite System), Galileo and Beidou are available, enabling the location in geographical coordinates to allow navigation. Due to the attenuation of satellite signals by building roofs and other obstacles, it is almost impossible to use them indoors, so indoors RTLSs are being developed, allowing realtime location in local coordinates for a given building or environment. Such systems are increasingly used, enabling indoor navigation, optimization and improving manufacturing processes. They enable, among others, indoor navigation, materials and product tracking, assets management, optimization of production systems, automatic process control based on location, access control, providing information on the location of people, animals, means of transport and ensuring security, and so forth [6]. Determining the location of objects in real time in a local indoor coordinate system (inside buildings) is the task of the systems referred to as RTLS. Unlike widely used outdoor RTLS systems operating on a global scale (e.g., GPS), indoor RTLSs are still at the stage of developing new solutions that meet the requirements of specific applications. The most common typical solutions use radio waves (UltraWideband, Wi-Fi, RFID—Radio Frequency Identification, Bluetooth, etc.), infrared, lasers or ultrasound [7].

The article presents the preliminary part of the research work aimed at developing a method for accurate determination of the location over a distance of about $30 \mathrm{~m}$ in hard coal mine conditions. Expected work conditions and requirements are quite different here than in the case of typical RTLSs used in manufacture processes and assets management $[6,8]$. In the described case, a much higher accuracy of distance measurement (millimetres) at distances of about $25-30 \mathrm{~m}$ is required, as well as the ability to operate in harsh environmental conditions, including obstacles typical for standard indoors RTLSs, such as walls and other objects blocking, reflecting and diffusing signals. Additional difficulties include explosion hazard, high pollution, dust and humidity, vibrations, noise, and air mass movement associated with the need for intensive ventilation. Additionally, the developed solutions must comply with the legal regulations that do not allow certain technologies to be used in a coal mines due to specific conditions (risk of methane and coal dust explosions).

The physical foundations of available technologies and the impact of conditions on accuracy and reliability for determining the location are discussed. The selected solution will be the basis for further work, allowing the designing and testing of the location system, able to determine the coordinates of objects in given conditions, with high accuracy and taking into account environmental and legal restrictions. The obtained location data can be used to control the movement of a roadheader in mine roadways.

Due to legal restrictions, the expected accuracy of measurement over a selected distance (these criteria make it difficult to use radio-based technologies), problems arising from a difficult work environment (high dust concentration and vibrations hindering the use of lasers for distance measurements), it was decided to focus on solutions based on ultrasound technology [9]. This article presents, among others, characterization of the future system operating conditions, theoretical foundations of using the ultrasound to measure distances, assessment of available devices and technologies, as well as the designed test devices and methodology, the selection of ultrasonic devices and auxiliary equipment. Tests of the selected devices were carried out in different conditions (different distances, different types of ultrasonic transducers, no forced air movement or forced air movement in different directions, etc.). Thanks to this part of research (the selection of devices allowing 
for accurate distance measuring), designing a complete location system (RTLS) that is able to operate in underground mine conditions will be possible in the next stage.

\section{RTLS Operating Conditions and Legal Restrictions in a Hard Coal Mine}

RTLSs are increasingly used to track and locate objects not only in the external environment (GPS), but also inside buildings (e.g., production halls). Compared to the outside environment, positioning inside buildings requires greater precision and is a more difficult task, mainly because different objects obscure, reflect and diffuse the used signal. There are the following five main quality parameters for indoor location systems [10]: system accuracy, range, latency in locating updates, impact of infrastructure on the building, impact of random system errors (such as errors due to signal interference and reflections). The planned use of the system in coal mine conditions makes it necessary to take into account additional restrictions, related to safety and the stronger impact of air movement, dust, temperature and humidity, as well as a large number of objects causing signal interference, than that on typical buildings.

The proposed location system is intended to enable the development of autonomous control systems for devices moving in confined interiors of buildings or corridors (e.g., forklifts, automated guided vehicles AGV or mobile machines and equipment). The positioning system, which allows the determination of the current position of the machine in the working environment with appropriate accuracy is one of the necessary components for the autonomous control of such machines [11].

Dust is the worst factor accompanying roadway development. The following factors decide the amount of dust generation-type of the mined rocks, the type of cutting tools, the type of water spraying nozzles and the cutting speed. In turn, the effectiveness of dust suppression depends on a properly designed ventilation, dust control and spraying system [12]. Analysing the literature [13,14], it can be concluded that the average speed of particles in air moving along the workings does not exceed $1 \mathrm{~m} / \mathrm{s}$. This is confirmed by the Polish regulations specifying that the speed of air stream in the working ventilated with the use of a duct should be at least $0.15 \mathrm{~m} / \mathrm{s}$ or $0.3 \mathrm{~m} / \mathrm{s}$, depending on the degree of methane hazard [15]. When it is ensured that the permissible gas contents and the appropriate climatic conditions are maintained and the cross-section area of the roadway is greater than $20 \mathrm{~m}^{2}$, the flow rates can be even lower. The arrangement of the ventilation ducts that supply and receive air is also important. The developed roadways have sucking, forcing and combined (sucking and forcing) ventube ventilation systems. Depending on the ventilation system, type of air flow in the working's face can be different. During the operation of a roadheader, large amounts of dust are generated, which should not be spread throughout the rest of the mine. Therefore, both local supply of air to the face of the mine heading and its extraction are usually used. The ways to ventilate the face of the mine heading may vary, Figure 1 shows one of the possible configurations together with the visualization of the air flow velocity. It should be assumed that there are significant air movements in the face of the mine heading, which may affect the measurements, therefore it is justified to conduct tests taking into account various combinations of the intensity and directions of air movements.

The maximum dust concentration in the face of a road heading drilled with a roadheader usually does not exceed $100 \mathrm{mg} / \mathrm{m}^{3}$ [14,16]. It is an average value due to the most frequently used measuring method with gravimetric dust meters; however, the instantaneous concentration may be several times higher than the averaged one. Thus, a maximum instantaneous dust concentration of hundreds of $\mathrm{mg} / \mathrm{m}^{3}$ can be expected under extremely difficult conditions. The regulations [15] stipulate that the maximum allowable concentration of dust in the mine at the workplace may not exceed the range from 1 to $10 \mathrm{mg} / \mathrm{m}^{3}$ (depending on the content of free silica). 

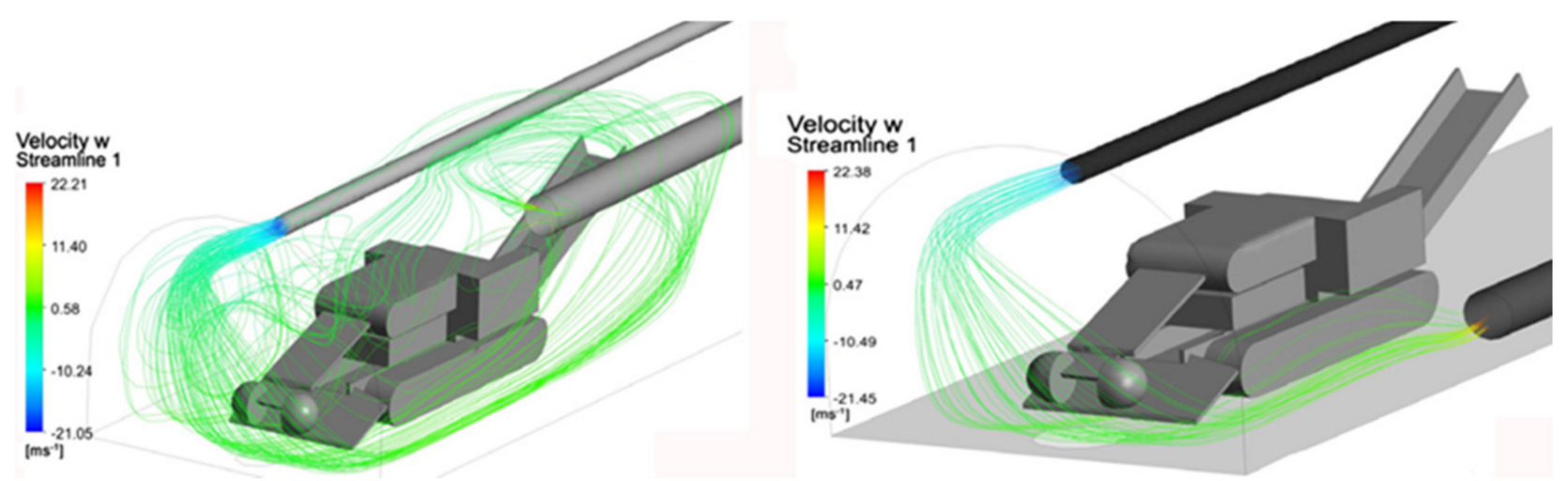

Figure 1. Visualization of the air flow velocity in the face of the mine heading. Reprinted with permission from ref. [14] Copyright 2011 Elsevier.

Air temperature in the mine depends on the temperature of the air supplied, its pressure, the temperature of the rocks, intensity of ventilation, the depth to which the air is supplied through the shaft, chemical reactions taking place in the rocks or mine workings, and other factors caused by the work of people and machines and blasting [17]. The temperature of the rocks increases with the depth of mining. For this reason, high temperatures can be expected in coal mines where work is carried out at great depths, especially in the face of bored tunnels. According to the regulations [15], temperature at the miners' workplace should not exceed $28^{\circ} \mathrm{C}$.

Therefore, in the case of the system being developed, limitations stems from two main groups, resulting from harsh environmental conditions (technical restrictions) and formal or legal restrictions.

Technical disturbances that affect the RTLS concept include:

- dust generated by technological processes in the vicinity of the machine, or by the machine itself, combined with forced air movement (ventilation); the expected average velocity of air particles in the machine working environment should not exceed $1 \mathrm{~m} / \mathrm{s}$; the maximum dust concentration should not exceed $100 \mathrm{mg} / \mathrm{m}^{3}$; at this point we neglect the fact that dust may cause explosion hazard, this is mentioned in the section on legal restrictions; here, we consider its impact on the accuracy and range of the location system,

- $\quad$ possible changes of temperature, also change conditions of signal transmission; it is necessary to determine the impact of temperature on the measured values in order to compensate it, expected range of temperature varies from 10 to $40^{\circ} \mathrm{C}$,

- noise and vibration, forcing the selection of devices and methods insensitive to this interferences, or to apply additional measures reducing the impact of vibration, e.g., using platforms that reduce vibrations or actively eliminate them; in the case of noise, it is possible to exclude some solutions that are difficult to protect against noise; RTLS operation should also not cause additional noise audible to workers in the vicinity of the system,

- $\quad$ high or variable humidity, leading to changes in signal transmission conditions and influencing measuring devices itself (corrosion),

- movement of air due to intensive ventilation, may have a different impact on the accuracy of measurements in some technologies, it may be dependent on the direction and speed of air flow.

Most of the legal restrictions result from safety reasons, mainly explosion hazards, listed in [4]:

- the prohibition on certain measurement or communication technologies (e.g., high energy laser radiation), 
- $\quad$ the prohibition on direct use of certain materials, which can only be used when placed in an appropriate enclosure, which, however, may cause additional difficulties, e.g., limit the range of signal transmission,

- all devices must meet leak tightness requirements and be approved for work in the area of explosion hazard (operation in explosive dust or gases).

There may also be additional restrictions, for example:

- relatively short locating distance-it's difficult to use RF (radio frequency) technologies with enough accuracy on short distances [11],

- the system should allow easy movement, placement and fixing of devices, as well as easy calibration,

- $\quad$ the space covered by RTLS may have an elongated shape of a small cross-section area limited by curved walls causing additional signal reflections (corridors).

Equipment and systems implemented in underground workings of coal mines must meet the requirements of the ATEX Directive 2014/34/EU [4] in the field of explosion protection. All these factors should be taken into account when selecting the location method, compensation algorithms and technical solutions used in the RTLS being developed. Many of the standard solutions used in tunnelling in environments other than coal mines cannot be used due to the described technical or legal constraints [2,3].

When developing a system for measuring distance and location in the conditions of a hard coal mine, the importance of problems such as the properties of rocks in which corridors are drilled [18,19], dripping water and humidity, dust, roadway linings [20], machines, ventilation ducts and other objects that may cause disturbances, reflections and attenuation of signals used for distance measurement should be emphasized. Due to all these factors and legal limitations, it was decided to adopt the assumption that the developed method requires the direct visibility of the transmitter and receiver (LoS-Line of Sight) in order to obtain a correct measurement result. The results obtained by receiving the reflected signals should be ignored.

\section{Distance and Location Measuring Methods}

Location determination methods can be classified according to various criteria, such as general system concept, measurement technologies and algorithms, signal transmission technology, the need to use labels or electronic devices placed on localized objects (active and passive systems) [21].

The methods for determining the position of objects moving in space can be divided into two main groups [11]:

- relative (incremental) - require taking into account the initial conditions and information about the movement trajectory; they are based on measurements taken only in the local coordinates system of the machine,

- absolute (static) - the location is determined in relation to the set reference system associated with the machine surrounding, without the need to refer to the movement trajectory.

The methods belonging to the first group (e.g., odometry and inertial methods) are usually easy to implement, have good short-term accuracy and high dynamics. Accumulation of errors during long-term work is their biggest disadvantage. These methods rely on position estimation based on velocity measurement or triaxial acceleration measurements, the values of which are converted into machine speed and displacement. In practice, apart from accelerometers, the gyroscopes should be used to stabilize the measuring platform, eliminating the impact of disturbances caused by the machine vibrations [11]. Systems from this group do not require external reference systems, but due to the relativity of indications they are not accurate enough, especially in the case of application in the expected conditions [22].

The methods representing the second group use environmental elements (sensors, tags or transmitters) with known coordinates to determine the location of the object. 
Calculations are made on the basis of specific geometrical relationships [23]. These methods, unlike the previous ones, are characterized by long-term accuracy, because in this case there is no accumulation of errors. A greater impact of disturbances on the measurement accuracy, resulting from the technical limitations of sensors, environmental conditions or signal delays may be the disadvantage.

The most common locating systems are usually based on radio waves (UltraWideband, Wi-Fi, Bluetooth, RFID, etc.), infrared, cameras, lasers or ultrasound [24]. The technologies of measuring the signal transmission are characterized by different errors at the expected ranges $[21,25,26]$, which are shown in Figure 2.

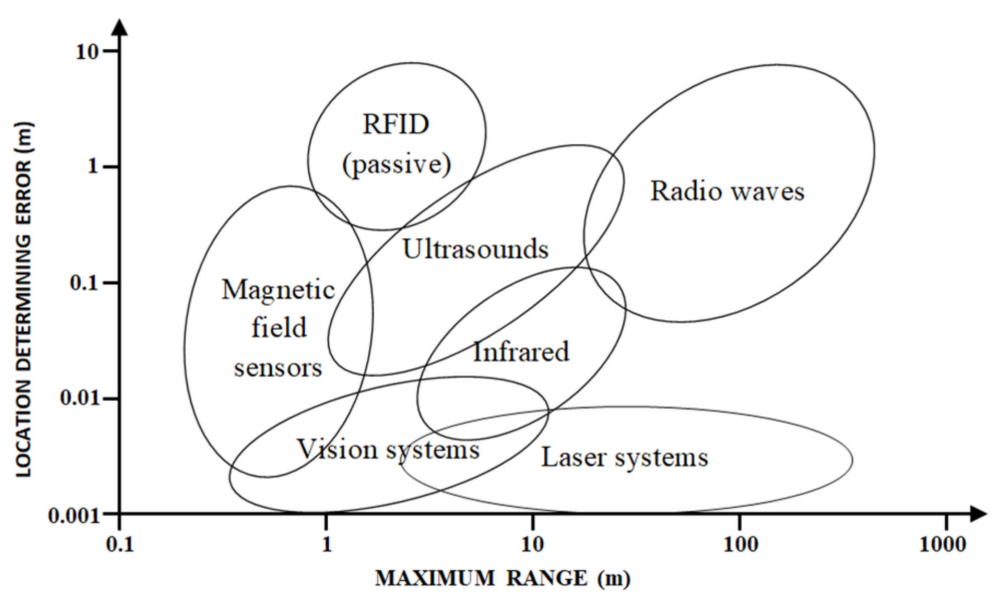

Figure 2. Classification of technologies for the location of indoor objects.

Preliminary analysis shows that systems using passive RFID transponders and magnetic field sensors have too short a range. Systems using infrared emitting components also have a short range, and they are also less accurate than laser technology systems. Laser systems are characterized by high accuracy, but their disadvantage is the need to ensure direct visibility between the emitters and receivers. The greatest range is achieved by the systems using radio technology, but their disadvantage is the lower accuracy of location, especially over short distances. Systems that use ultrasound may be an alternative solution. They have a shorter range but better accuracy. Their sensitivity to the properties of the propagation environment is a disadvantage.

\section{Measurement Techniques Used to Locate Objects}

Determination of the position using the phenomena related to the propagation of electromagnetic waves requires the use of appropriate measurement technologies [25-27]. The most common measurement technologies used in RTLSs are presented in Figure 3.

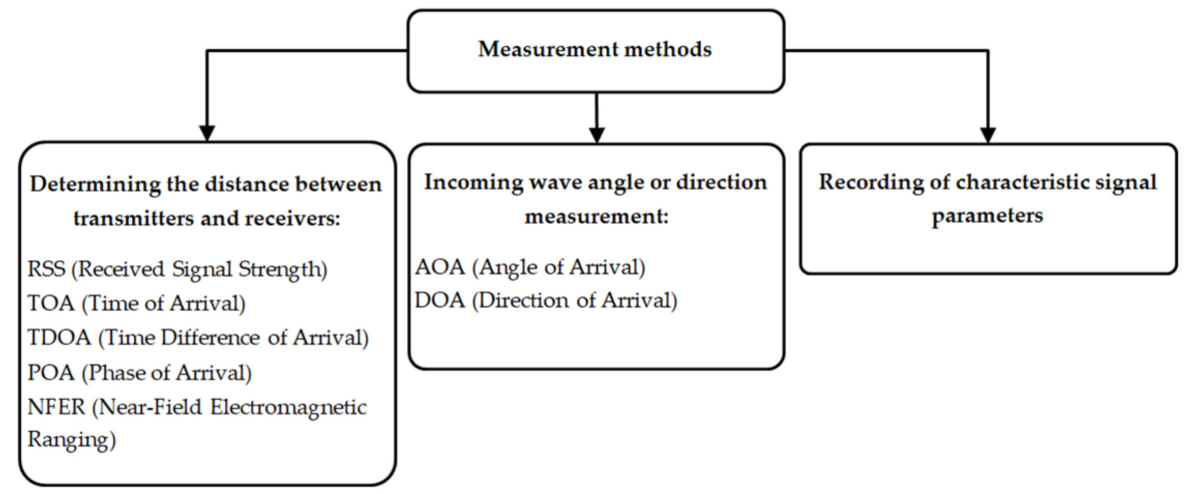

Figure 3. Measurement technologies used in location systems. 
Determination of the distance on the basis of the RSS (Received Signal Strength) requires knowledge of the attenuation of the adopted wave propagation channel model, therefore it is difficult in the expected environmental conditions. The next two techniques involve determining the distance based on the timing relationships between received signals: TOA (Time of Arrival) and TDOA (Time Difference of Arrival). Both methods require precise timing of signal reception. TOA is a measurement of the propagation time between a system transmitter and receiver. By knowing the speed of propagation, it is possible to calculate the distance [28]. The TDOA method is based on determining the time difference between the signals reaching the receiver or receivers [29]. Both methods require synchronization of measurements. The POA (Phase of Arrival) method enables distance determination based on the phase difference of sinusoidal signals, which is difficult to implement in the case of rooms. Another method is NFER (Near-Field Electromagnetic Ranging), which uses the relationship between the electric and magnetic field phases, but only in the near field of the transmitting antenna. Another method is to measure the AOA (Angle of Arrival) or DOA (Direction of Arrival) of wave. The directions from which the waves reach several antennas become information about the location of the transmitter. Measurements most often use sector or rotating antennas (tracking the signal with the highest intensity), which is technically more complicated. Recording the signal characteristics, where the information about the position is determined on the basis of information encoded in the parameters of signals received at a given location, is the last group. The algorithm for determining the position is based on comparisons with previously recorded patterns.

Due to environmental limitations and ease of measurement, further work has been focused on TOA and TDOA distance measurement technologies.

\section{Assessment of Available Technical Solutions of Distance and Location Measuring}

In industrial applications, two types of waves are most often used to determine the position of an object in space: acoustic or electromagnetic. The first type of waves is used in the ultrasound range, with frequencies higher than the band that can be heard by the human ear so as not to affect the working environment. On the other hand, electromagnetic waves are used mainly in the range of radio waves, including microwaves or a laser beam, is used. When selecting the appropriate measurement technology, the conditions in the expected RTLS application locations were also taken into account.

Figure 4 shows the areas of effective use of the appropriate measurement technology, analysed in terms of the measurement distance and dust concentration, which is one of the main disturbing factors in the expected operating environment of the system [30]. The presented diagram shows that all technologies can be used at the expected possible dust level $\left(100 \mathrm{mg} / \mathrm{m}^{3}\right)$, in relation to the expected measurement distances. On the other hand, radio waves are the most dust resistant. According to the adopted rules, microwaves also belong to the group of radio waves. These are the waves with a frequency in the range from $300 \mathrm{MHz}$ to $3000 \mathrm{GHz}$.

As the work focuses on the practical use of the results, that is, the implementation of the developed method by selecting the measurement technology, the suitable measuring devices available on the market, which could be practically applied were analysed [31-35]. They were divided into nine groups presented in Figure 5.

Then, the equipment included in each group was assessed in terms of their use in the positioning system of a roadheader in a hard coal mine. For this purpose, Figure 6 was created, in which the groups of devices presented in Figure 5 were compared with the criteria relevant to the application. Selection of the evaluation criteria was guided by the results of the analysis of available technologies and algorithms, presented in the previous chapters. The choices of the TOA measurement method and the trilateration algorithm were the main factors influencing the criteria. 


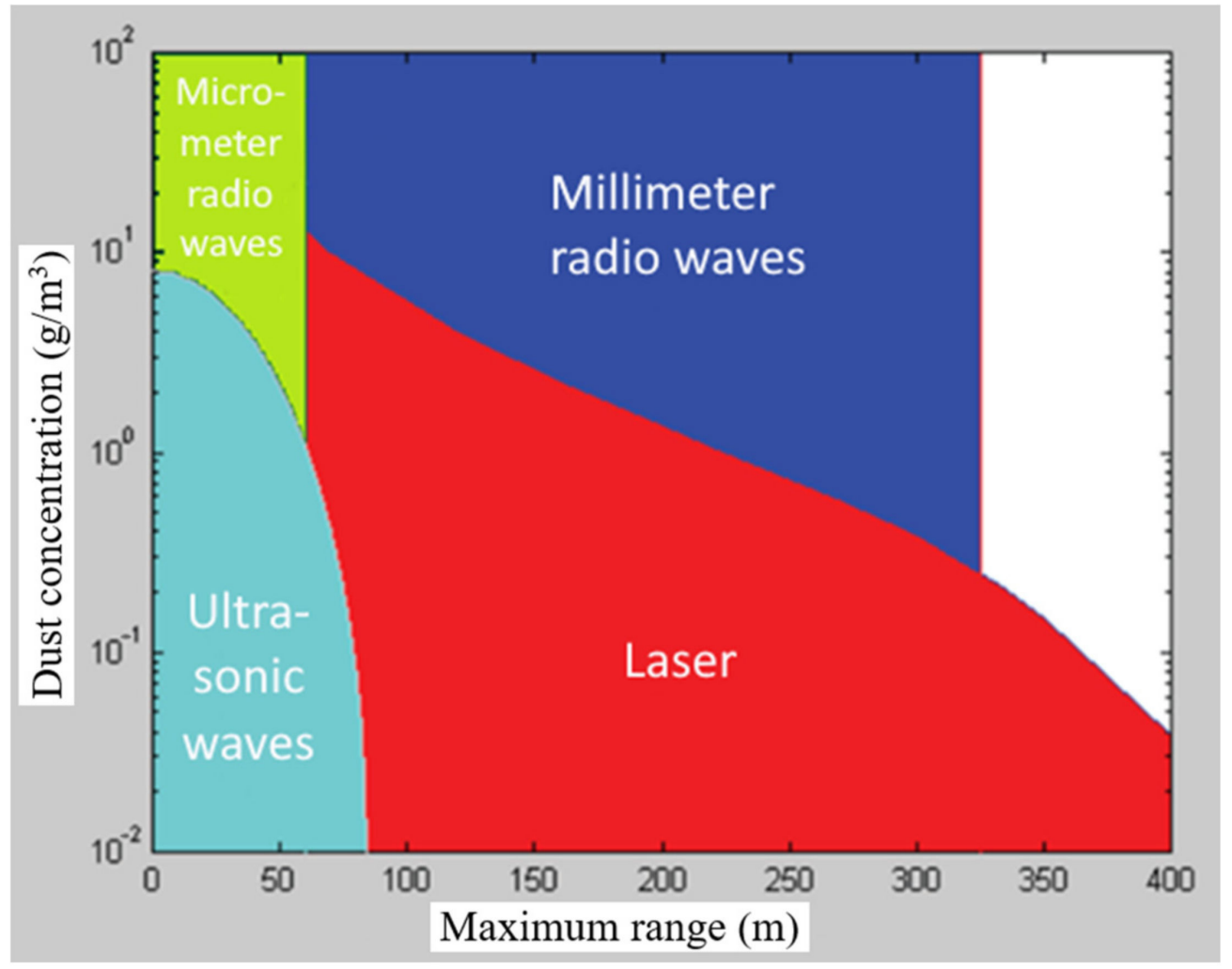

Figure 4. Graph of the effective selection of the appropriate measurement technology. Adapted from ref. [30].

\begin{tabular}{|c|c|c|}
\hline Laser & Acoustic waves (ultrasound) & Radio waves \\
\hline Rangefinder & Ultrasonic sensors & Radio communication modules \\
\hline Tachimeter/ Theodolite & Level measuring heads & Radar level measurement \\
\hline & & \\
\hline Scanner & Ultrasonic transducers & Radio distance measurement \\
\hline
\end{tabular}

Figure 5. Types of devices using various measurement technologies. 


\begin{tabular}{|c|c|c|c|c|c|c|c|c|c|c|}
\hline & 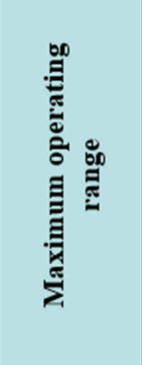 & 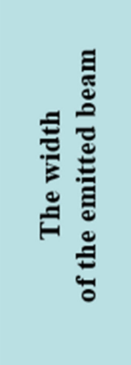 & 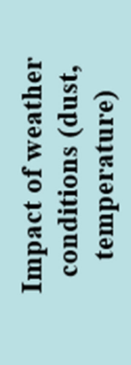 & 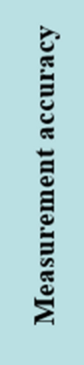 & 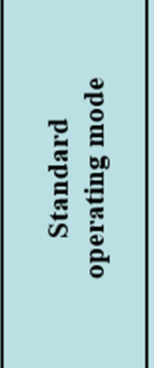 & 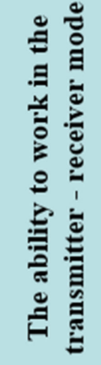 & 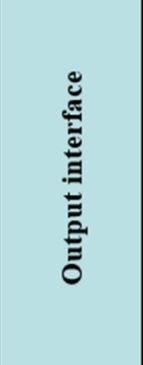 & 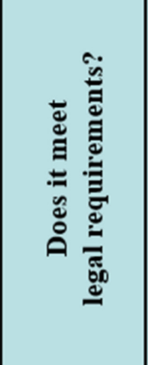 & हैं & 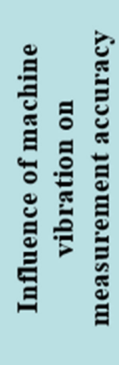 \\
\hline $\begin{array}{c}\text { Ultrasonic distance } \\
\text { sensors }\end{array}$ & $\begin{array}{l}\max .10 \mathrm{~m} \\
\text { (echo) }\end{array}$ & \multirow{2}{*}{$3^{\circ} \ldots 15^{\circ}$} & \multirow{3}{*}{ yes } & \multirow{3}{*}{ good } & echo mode & no & standard & \multirow{3}{*}{$\begin{array}{l}\text { usually, } \\
\text { after some } \\
\text { modification }\end{array}$} & cheaper & no \\
\hline $\begin{array}{l}\text { Ultrasonic level } \\
\text { measuring heads }\end{array}$ & $40 \mathrm{~m}$ (echo) & & & & $\begin{array}{l}\text { most often } \\
\text { the echo } \\
\text { mode }\end{array}$ & selected & $\begin{array}{l}\text { usually } \\
\text { standard }\end{array}$ & & cheaper & no \\
\hline $\begin{array}{l}\text { Ultrasonic } \\
\text { transducers }\end{array}$ & $\begin{array}{l}\text { no data } \\
\text { available }\end{array}$ & $\sim 30^{\circ}$ & & & any & yes & $\begin{array}{l}\text { own } \\
\text { control } \\
\text { system }\end{array}$ & & cheaper & no \\
\hline Laser rangefinder & $\begin{array}{c}65 \mathrm{~m} \\
(>100 \mathrm{~m} \\
\text { with } \\
\text { reflector })\end{array}$ & point & \multirow{3}{*}{ yes - dust } & \multirow{3}{*}{ good } & $\mid \begin{array}{r}\text { reflected ray } \\
\text { (echo mode) }\end{array}$ & no & standard & $\begin{array}{c}\text { in } \\
\text { flameproof } \\
\text { enclosure }\end{array}$ & average & yes \\
\hline Laser theodolite & $>50 \mathrm{~m}$ & point & & & $\begin{array}{l}\text { ray reflected } \\
\text { from prisms }\end{array}$ & no & digital & no & expensive & yes \\
\hline Laser scanner & $10 \ldots 80 \mathrm{~m}$ & $\begin{array}{c}180^{\circ} \\
\text { continuous } \\
\text { scanning }\end{array}$ & & & $\begin{array}{l}\text { reflected } \\
\text { ray }\end{array}$ & no & digital & no & expensive & yes \\
\hline $\begin{array}{c}\text { Radio } \\
\text { communication }\end{array}$ & $500 \mathrm{~m}$ & wide angle & \multirow{3}{*}{ no } & \multirow{3}{*}{ worse } & $\begin{array}{l}\text { transmitter- } \\
\text { receiver }\end{array}$ & yes & $\begin{array}{c}\text { ready-made } \\
\text { module }\end{array}$ & usually & cheaper & no \\
\hline $\begin{array}{l}\text { Radar level } \\
\text { meters }\end{array}$ & $70 \mathrm{~m}$ & $20^{\circ}$ & & & $\begin{array}{l}\text { reflected } \\
\text { wave }\end{array}$ & no & standard & usually & average & no \\
\hline $\begin{array}{c}\text { Radio distance } \\
\text { measurement }\end{array}$ & $500 \mathrm{~m}$ & $<10^{\circ}$ & & & $\begin{array}{l}\text { transmitter- } \\
\text { receiver or } \\
\text { echo mode }\end{array}$ & yes & standard & no & average & no \\
\hline
\end{tabular}

Figure 6. SWOT evaluation of measuring devices.

Figure 6 presents an evaluation method based on modified SWOT analysis. In addition to the descriptive evaluation, colour marking was used. Areas that definitely eliminate a given group of devices are marked in red. The yellow colour marks areas that introduce certain restrictions, but do not eliminate a given type of device. The strengths that represent the advantage of a given group are highlighted in green. Non-Decisive accepted areas were left unmarked.

Among the group of assessed devices, ultrasonic transducers and heads, as well as radio communication modules, were distinguished such that they could be used in the planned application. In the case of laser devices (other than low-power rangefinders), there is a problem with certification for operation in assumed explosion hazard conditions (mainly due to the limitations resulting from the work environment and the requirements of the ATEX directive). In addition, the method for measurements with the use of a laser is 
impractical due to the need to use the screens and due to possible machine vibrations. As a result, laser-based technology was excluded from the solutions taken into account in the RTLS being developed.

Radio systems have a high measuring range and high resistance to weather conditions; however, the implementation of short distance measurements (which are expected in the planned application of the developed system) is technically quite complicated and has low accuracy.

Until now, ultrasonic systems have been relatively rarely used in harsh environmental conditions, but the speed of propagation of ultrasonic waves, amounting to about $340 \mathrm{~m} / \mathrm{s}$, should ensure good accuracy of measurements at the assumed distances. From this group of devices, only ultrasonic heads have a satisfactory measuring range. In the case of using the ultrasound technology, more detailed tests will be necessary, allowing determination of the impact of various factors (such as changes in temperature, humidity, dust, air movement) disturbing the measurements accuracy. It is also difficult to extend the range of ultrasonic devices over much greater distances.

\section{Analysis Results}

The analysis showed that passive solutions and those that absolutely require direct visibility of location transmitters and receivers can be rejected at the outset. In the system concept category, relative systems (incremental - requires taking into account the initial conditions and information about the movement trajectory; they are based on measurements taken only in the local system of the machine) can be rejected, and only absolute systems (static - the location is acquired in relation to the outside reference objects without having to refer to the movement trajectory) should be considered.

Methods for determining the position of objects in space taken into account are mostly based on measurements of distance between receivers and transmitters [23]. Thus, the design of distance and location measuring system for a roadheader in a hard coal mine focuses on this technology due to the fact that automated accurate angle measurements can be troublesome under the assumed conditions, which are also obstacles in the successful application of technologies based on recording and comparing the characteristic parameters of signals [7]. Determining the distance on the basis of the received signal strength requires knowledge of the attenuation of the adopted wave propagation channel model, therefore it is difficult to implement it in the conditions, characterized by significant disturbances [36].

It was assumed that in the expected configuration of the measuring environment, the methods requiring the measurement of the angles cannot be practically applied, which leaves at the disposal the methods based on determining the distance based on the propagation time of signals (TOA or TDOA). The TOA measurement technology using radio or ultrasound waves and the positioning method based on the trilateration principle were considered the most promising. The justification is the relatively simple design of the transmitting-receiving and measuring systems. In addition, the use of slower sound waves should ensure high measurement accuracy, and the reliance on wave phenomena should result in greater resistance to various types of interferences in the demanding and difficult environment, which is planned as a potential application site for the RTLS being developed.

\section{Selected Properties of Ultrasonic Waves}

As a result of analysis, it was assumed that the distance measurements will use the TOA method and ultrasonic technology.

The acoustic (ultrasonic) wave is the vibration of the elastic medium particles, propagating in the form of a longitudinal wave [37]. In a heterogeneous medium, the shape of the ultrasonic signal is influenced by:

- composition heterogeneity (e.g., difference in density),

- heterogeneity of the physical state (e.g., temperature difference),

- foreign bodies inclusions (e.g., dust, water droplets in the air),

- $\quad$ medium movements (e.g., flow, turbulence). 
The distance between the transmitter and receiver is given by the following Equation (1) [27]:

$$
\mathrm{d}=\Delta \mathrm{t} \frac{\mathrm{v}_{\mathrm{RF}} \cdot \mathrm{v}_{\mathrm{US}}}{\mathrm{v}_{\mathrm{RF}}-\mathrm{v}_{\mathrm{US}}}(\mathrm{m})
$$

where: $\Delta \mathrm{t}$-time difference between receiving both signals in the receiver, vUS - ultrasonic wave propagation speed, $\mathrm{v}_{\mathrm{RF}}$-radio wave propagation speed.

The speed of a radio wave is about one million times greater than that of a sound wave. For example, a sound wave travels a distance of $20 \mathrm{~m}$ in about $58.8 \mathrm{~ms}$ (assuming $\mathrm{v}_{\mathrm{US}}=340 \mathrm{~m} / \mathrm{s}$ ), while a radio wave travels this distance in about $7 \mathrm{~ns}$, which is only $12 \%$ of that value. When neglecting the small radio wave propagation time, the Equation (1) can be simplified to the following Equation (2) [22]:

$$
\mathrm{d}=\mathrm{v}_{\mathrm{US}} \cdot \Delta \mathrm{t}(\mathrm{m}) \text {. }
$$

The measurements conditions must also be taken into account. Therefore, it was assumed that the acoustic wave would be sent in the form of a short pulse, and the moment of receiving the wave front will be measured. Thus, the wave that has travelled the shortest path, without obstacles, will be measured with the LOS (Line of Sight) method [11,21,26]. In this way, the negative impact of phenomena accompanying the wave propagation, such as reflections from the walls of a corridor, will be reduced [38].

Propagation velocity and attenuation of the medium are the most important acoustic parameters of the gaseous medium in which the ultrasonic waves propagate. These two parameters have the most decisive impact on the nature of changes in ultrasonic signals propagated in this type of medium [37-39]. The speed of ultrasonic wave propagation in gases is given by the following Equation (3) [37]:

$$
\mathrm{v}_{\mathrm{US}}=\sqrt{\frac{\kappa(\mathrm{T}) \mathrm{p}_{0} \mathrm{~T}}{\rho_{0} \mathrm{~T}_{293}}}\left(\frac{\mathrm{m}}{\mathrm{s}}\right),
$$

where: $\rho_{0}$ - gas density in normal conditions, $\mathrm{p}_{0}-$ gas pressure in normal conditions, $\mathrm{T}$ gas temperature, $T_{293}=293 \mathrm{~K}, \mathrm{k}(\mathrm{T})$-dimensionless adiabatic exponent equal to $\mathrm{c}_{\mathrm{p}} / \mathrm{c}_{\mathrm{V}}$, $c_{p}$-specific heat at constant pressure, $c_{v}$-specific heat at constant volume.

The coefficient $\kappa(\mathrm{T})$ depends on the temperature, but to a small extent also on the pressure of the gaseous medium. Within the range of gas pressure changes of $810-1216 \mathrm{hPa}$, it has a constant value (in the air at $20^{\circ} \mathrm{C}$ it is 1.4). Taking into account the above fact and analysing the Equation (3), it can be assumed that the speed of propagation of ultrasonic waves in air does not depend on its pressure. This statement is correct in terms of pressure values close to atmospheric. The speed of ultrasound propagation in air depends the most on its temperature. The higher the air temperature, the faster its particles move and the greater their velocity $[37,38]$. The temperature coefficient of the velocity of sound vUS $(\mathrm{T})$ is very similar to the linear velocity coefficient in the temperature range $-5-100{ }^{\circ} \mathrm{C}$, so it can be expressed as a derivative of velocity in relation to temperature. Assuming the linear form of the $\mathrm{v}_{U S}(\mathrm{~T})$ curve, we can transform the Equation (3) into the following Equation (4) [37,40]:

$$
\mathrm{v}_{\mathrm{US}}=\mathrm{v}_{\mathrm{US} 0}+\mathrm{bT}=\mathrm{v}_{\mathrm{US} 0}(1+\mathrm{b} / \mathrm{T})\left(\frac{\mathrm{m}}{\mathrm{s}}\right)
$$

where: $\mathrm{V}_{\mathrm{US} 0}$ - speed of sound at $\mathrm{T}_{0}, \mathrm{~b}$ - temperature coefficient of speed of sound equal to $\Delta v_{U S} / \Delta T$ in relation to $T_{0}, b^{\prime}$-relative temperature coefficient of speed of sound, $b^{\prime}=b / v_{U S 0}$. Gudra [37] and Manthey et al. [38] assign the Equation (4) the value $\mathrm{V}_{\mathrm{US}}=331.85 \cdot(1+0.00183 \mathrm{~T})$.

By analysing the system of ultrasonic transducers (located in the air atmosphere coaxially at a given distance from each other), characterized by the same resonant frequency, 
where one is the wave transmitter and the other is the receiver, the equation for the range of the aeroacoustic link can be defined as (5) [37,39]:

$$
\frac{\mathrm{P}_{\mathrm{T}}}{\mathrm{P}_{\mathrm{R}}}=\frac{8 \pi \mathrm{c}^{2} \mathrm{~d}^{2} \mathrm{e}^{2 \zeta \mathrm{d}}}{\pi^{2} \mathrm{f}^{2} \mathrm{D}_{\mathrm{T}}^{2} \mathrm{~S}_{\mathrm{R}}},
$$

where: $\mathrm{P}_{\mathrm{T}}$ - power radiated by the transmitting transducer, $\mathrm{P}_{\mathrm{R}}$ - power received by the receiving transducer, $\mathrm{d}$ - distance between transducers, $\mathrm{f}$ - frequency of the ultrasonic wave, $\zeta$-amplitude damping coefficient in the air, $S_{R}-$ surface of the receiving transducer, $\mathrm{D}_{\mathrm{T}}$ - diameter of the transmitting transducer.

Equation (5) is correct provided that the condition $\pi \mathrm{fD}_{\mathrm{T}} / \mathrm{v}_{\mathrm{US}}>>1$ is satisfied. It allows estimation of the maximum distance between the transmitter and the receiver of ultrasonic waves, using specific models of transducers, but for this purpose the transmitting and receiving power of these transducers must be known, and the acoustic and physical parameters of the propagation medium must be precisely defined.

\section{Selection of a Type and Parameters of Ultrasonic Transducers}

The positioning method adopted for further work uses ultrasound (to measure TOA distance) and radio waves (auxiliary-for synchronization). Considering the application nature of the work, it is necessary to select the actual measuring elements. The phenomena accompanying the propagation of the ultrasonic wave will be of key importance, because the distance between each element of the system will be determined on the basis of the parameters related to this phenomenon [11].

Since ultrasonic waves are usually used in sensors with a range of up to several meters, it is necessary to select measuring elements that will cover the assumed measuring range (at least $\sim 25 \mathrm{~m}$ ). In this chapter, the ultrasonic waves and the parameters accompanying their propagation are characterized. Specifications of the ultrasonic wave transmitting and receiving elements were also checked and preliminary tests of selected ultrasonic transducers were carried out, testing the possibility of their practical application. In tests, the ready-made (purchased) components for generation and reception of ultrasonic waves, as well as the measuring/amplifying devices were used.

\subsection{Ultrasonic Transducers as a Transmitter and Receiver Devices}

Ultrasonic transducers, which most often can work both as a transmitter and a receiver are used to generate ultrasonic waves [41]. There are two main types of transducersmagnetostrictive (currently ousted from the market) and piezoelectric (of better technical parameters, including better conversion efficiency). Piezoelectric crystals are deformed due to the applied alternating electric field, as a result of which an electric charge appears on the surface of the deformed crystal [21]. The advantage is the linear transformation characteristic in a wide range of electric field changes and mechanical deformations.

The devices available on the market (ultrasonic transducers) intended for generating and receiving ultrasonic waves in the air were analysed. Two main groups of devices can be distinguished-ultrasonic sensors (most often used in automation and robotics systems, of relatively short range) and ultrasonic heads (components of bigger sizes, often used in heavy industry, used, among others, to measure the filling level of tanks with loose materials and liquid, often they are manufactured in hermetic form, of longer maximum range). It was found that the ultrasonic sensors have too short range for the intended application, so further work focused on the ultrasonic heads.

Maximum measuring range, resonant operating frequency, angle of transmission/reception of the signal, sensitivity, and other parameters or features were taken into account.

\subsection{Overview of Available Ultrasonic Transducers}

The maximum measuring range depends (apart from parameters of the medium) on the power of the transducers and their diameter. In the case of commercially available ultrasonic sensors, the operating range is limited to $\sim 15 \mathrm{~m}$. In some cases, the range is 
greater, but under the expected operating conditions, due to air pollution (dust, moisture), the required enclosure limits this range. Based on the comparison of the estimated range of this group of transmitters with the adopted assumptions, it was found that they do not meet the requirements of the planned application. Aluminium enclosure-is additional limitation in the use of some sensors as due to the requirements of the ATEX directive, this material is not approved for direct use in gas or dust explosion hazard conditions.

Ultrasound heads are the second analysed group of the components for generation and reception of ultrasonic waves. These are larger-sized components, often used in heavy industry, where they are applied, among others, for measuring the level of filling the tanks with loose (grains) and liquid materials or for detecting the presence of objects. For this reason, they are made in an airtight form. Manufacturers declare the maximum range of operation, when measuring the reflected wave, which is adequate to the assumptions. The list of ultrasonic heads available on the market and their technical parameters constituting the criterion for their selection is presented in Figure 7.

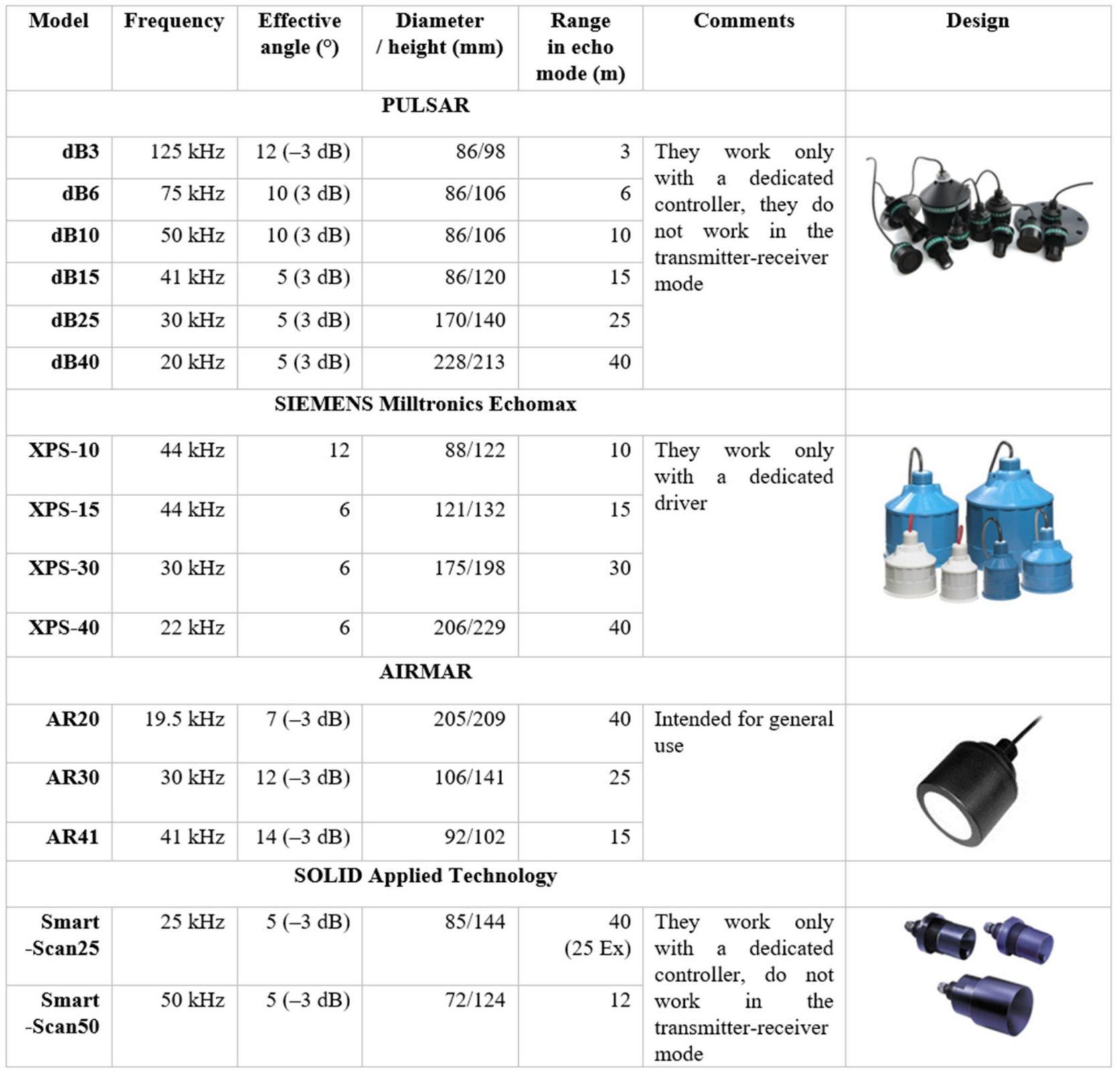

Figure 7. Parameters of ultrasonic transducers available on the market. 


\section{Ultrasonic Transducers Tests}

Ultrasonic transducers AR30 and AR41, manufactured by AIRMAR (Milford, NH 03055, USA), are designed for distance measurements in an air medium, and were selected as the transmitter and receiver of ultrasonic waves [42]. Initial tests aimed to check whether the ultrasonic technology is in line with the adopted assumptions. The tests were performed with the use of the T1 test module offered by the manufacturer of ultrasonic transducers for their operation. The range of AR30 and AR41 components was tested during operation in the "transmitter-receiver" mode. The impact of disturbances of the medium in which the waves are transmitted was also tested on the amplitude of the received signal and the propagation time. Measurements taken in an undisturbed medium were compared with the measurements taken after introducing the disturbances in the form of fans, set in various configurations to the propagation path. Components generating ultrasonic waves used to measure the distance in the air are usually designed to work in the echo mode, so the manufacturers indicate the maximum measuring range in this mode of operation. In the case of ultrasonic transducers, information on sensitivity and acoustic power is provided. The main parameter that distinguishes the AR30 and AR41 transducers is the operating frequency, which is also the resonant frequency of these components. The most important parameters of the selected elements are given in Table 1.

Table 1. Parameters of the selected ultrasonic transducers.

\begin{tabular}{ccc}
\hline Parameter & AR30 & AR41 \\
\hline Resonance frequency & $30 \mathrm{kHz}$ & $41 \mathrm{kHz}$ \\
Transmitter sound pressure level & $105 \mathrm{~dB}$ & $110 \mathrm{~dB}$ \\
Receiver sensitivity & $-155 \mathrm{~dB}$ & $-160 \mathrm{~dB}$ \\
Maximum transmitter excitation signal voltage (peak to peak) & $2200 \mathrm{~V}$ & $1800 \mathrm{~V}$ \\
\hline
\end{tabular}

The block diagram of the ultrasonic transducer test setup is shown in Figure 8. The test setup was located in the corridor of the building, which was intended to simulate some of the conditions in which the developed devices would operate. In this configuration, it was possible to test the impact of phenomena accompanying wave propagation, such as reflections, on the parameters of the received signal. The transmitter was placed on a sliding platform, the receiver was stationary. Both types of transducers (two pairs of AR30 and AR14) were used in tests and connected to the T1 module [42]. The transmitting part of the T1 module allows adjusting the frequency and amplitude of the voltage connected to the ultrasonic transducer. According to the manufacturer's information, the output voltage is regulated in the range of $200-500 \mathrm{~V}\left(\mathrm{~V}_{\mathrm{p}-\mathrm{p}}\right.$ - peak-to-peak voltage value). The receiving part of the $\mathrm{T} 1$ module enables the amplification of the signal received from the ultrasonic transducer in the range of $0,20,40,60 \mathrm{~dB}$. The amplified signal was recorded by a TDS2024B oscilloscope (Tektronix, Inc., Beaverton, OR, USA).

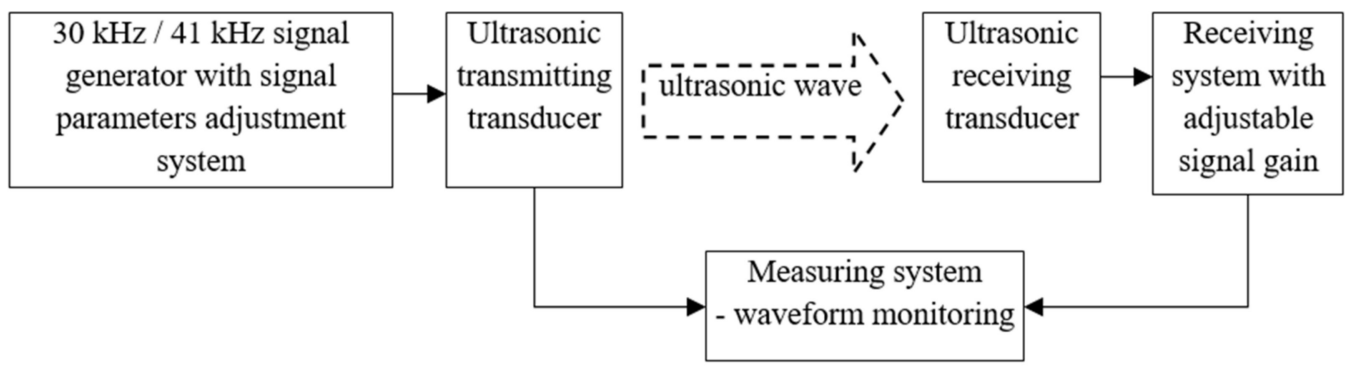

Figure 8. The test setup block diagram. 


\subsection{Preliminary Tests of Ultrasonic Transducers}

During the tests, the transmitting transducer was powered by an impulse signal $(3 \mathrm{~Hz})$, a single impulse meant an alternating, rectangular voltage signal with a frequency corresponding to the resonant frequency of the ultrasonic transducer and a duration of $2.5 \mathrm{~ms}$. The figures show the amplitudes of the voltage recorded in the receiver system at different distances between the receiver and the transmitter (from 5 to $40 \mathrm{~m}$, every $5 \mathrm{~m}$ ), and a series of 10 measurements were taken at each distance. Figure 9a shows the results of the test with the use of AR41 type transducers and two voltage levels of the excitation signal of transducers generating ultrasonic waves $(300 \mathrm{~V}$ and $516 \mathrm{~V}$-the maximum setting of the T1 module). Figure $9 \mathrm{~b}$ shows the results of the test with the use of AR30 type converters, the maximum voltage supplied to the transmitting converter was $450 \mathrm{~V}$.

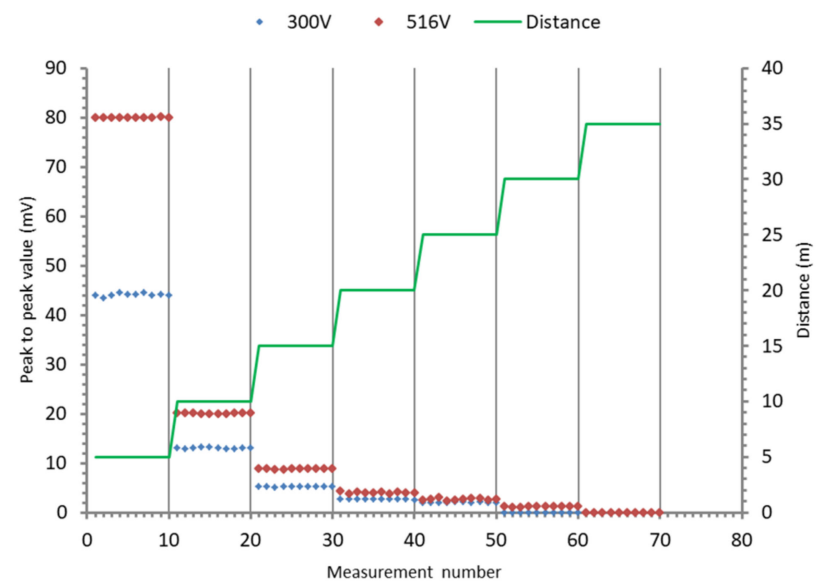

(a)

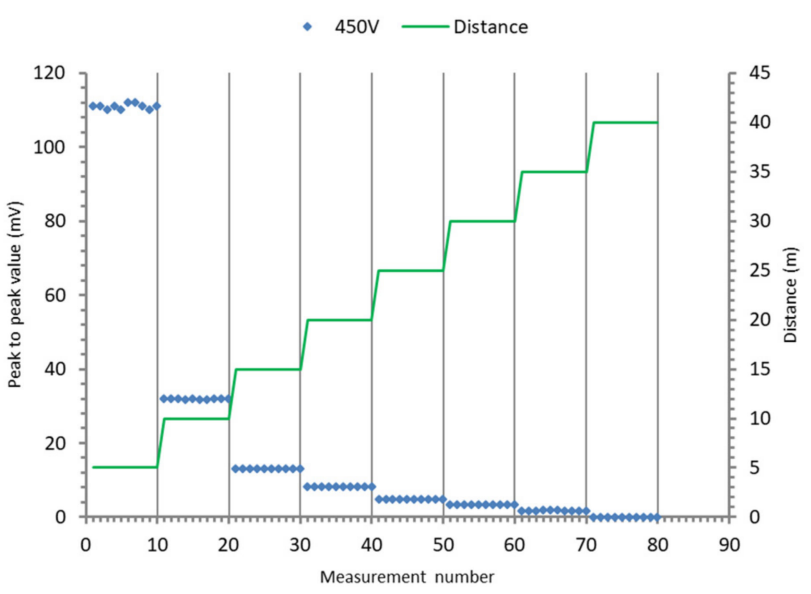

(b)

Figure 9. (a) Signal of voltage in the AR41 receiver at the $V_{p-p}$ voltage of the transmitter set to $300 \mathrm{~V}$ and $516 \mathrm{~V}$; (b) Signal of voltage in the AR30 receiver at the $\mathrm{V}_{\mathrm{p}-\mathrm{p}}$ voltage of the transmitter set to $450 \mathrm{~V}$.

Figure 10 shows the average voltage recorded in the receiver, for both types of transducers, AR30 and AR41, in relation to the distance between the transmitter and the receiver of ultrasonic waves. The intensity of the ultrasonic wave in accordance with the presented relationships decreases exponentially.

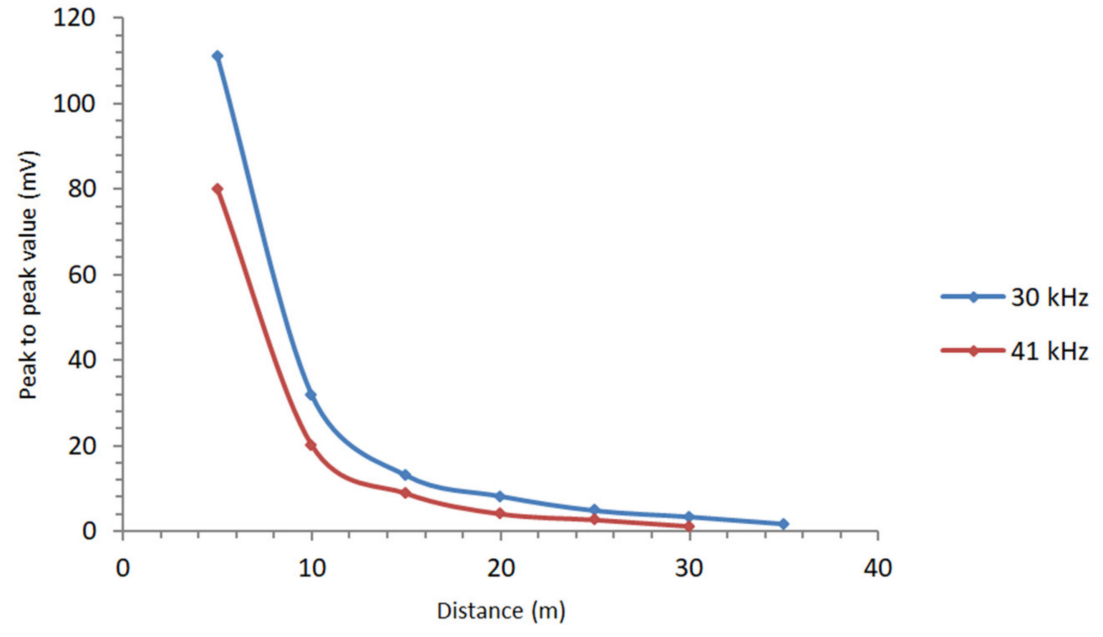

Figure 10. Averaged voltages recorded in the receiver (AR30 and AR41 transducers). 
Higher frequency ultrasonic waves are damped more. The effective measuring range, in relation to the adopted level of the excitation signal of wave-generating converters, was $30 \mathrm{~m}$ (AR41) and $35 \mathrm{~m}$ (AR30), which meets the requirements.

Figure 11 shows the propagation time of the ultrasonic wave in a function of the distance between the transmitting and receiving transducers. The measured propagation time at a constant measuring distance was constant. The propagation time for both types of ultrasonic transducers was the same. The speed of wave propagation does not depend on its frequency, but on the elastic properties of the medium. The relationship presented in Figure 11 takes the form of a linear function. On this basis, it can be concluded that in constant atmospheric conditions the measurement distance is directly proportional to the propagation time of ultrasonic waves.

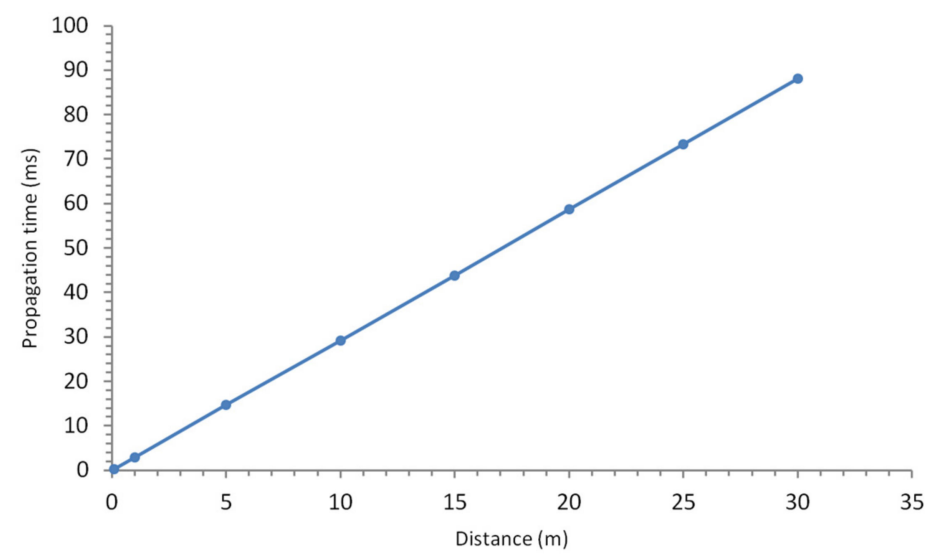

Figure 11. Dependence of propagation time of ultrasonic waves on the distance (AR30).

\subsection{Testing the Impact of Propagation Medium Disturbances on the Parameters of the Received Wave}

Measurement of the impact of disturbances in the wave propagation on the amplitude of the received signals and the measured wave propagation time was the next stage of testing. Disturbances in the form of fans (placed outside the signal propagation path) generating directionally forced air movements were introduced to the measuring setup. At the first stage of testing, the direction of air movement was consistent with the direction of propagation of ultrasonic waves. The measured wave propagation time in a disturbed medium was compared with the propagation time in an undisturbed medium and is shown in Figure 12. Measurements were taken for the distances between the transmitter and receiver equal to: 5, 10, 15 and $20 \mathrm{~m}$. In the case of a disturbed medium, fluctuations in the propagation time were observed.

The differences between the propagation times were small- the maximum absolute error, determined according to the Equation (6), in relation to the propagation time in the undisturbed medium was $120 \mu \mathrm{s}$. The maximum absolute error of time measurement in the disturbed medium at different distances between the transmitter and receiver was $0.045 \mathrm{~ms}$ (at the distance $5 \mathrm{~m}), 0.0275 \mathrm{~ms}(10 \mathrm{~m}), 0.063 \mathrm{~ms}(15 \mathrm{~m})$ and $0.12 \mathrm{~ms}(20 \mathrm{~m})$.

$$
\Delta \mathrm{t}=\left|\mathrm{t}-\mathrm{t}_{\mathrm{z}}\right|
$$

where $\mathrm{t}$-reference time (measured in an undisturbed medium), $\mathrm{t}_{\mathrm{z}}$ - time measured in a disturbed medium.

At the next stage of testing, the sources disturbing the wave propagation medium were set between the transmitter and the receiver, and 3 series of measurements were taken with different settings of fan airflow direction. The test setup and the schematic configuration of the disturbance sources are shown in Figure 13. 
a)

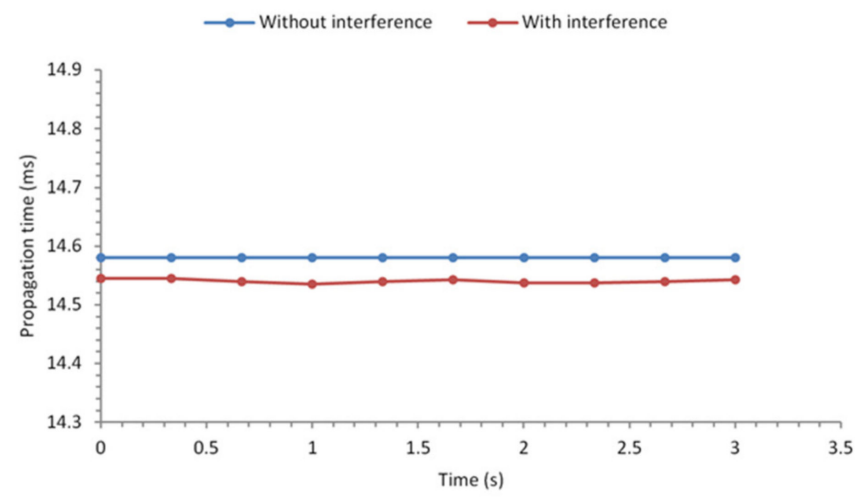

c)

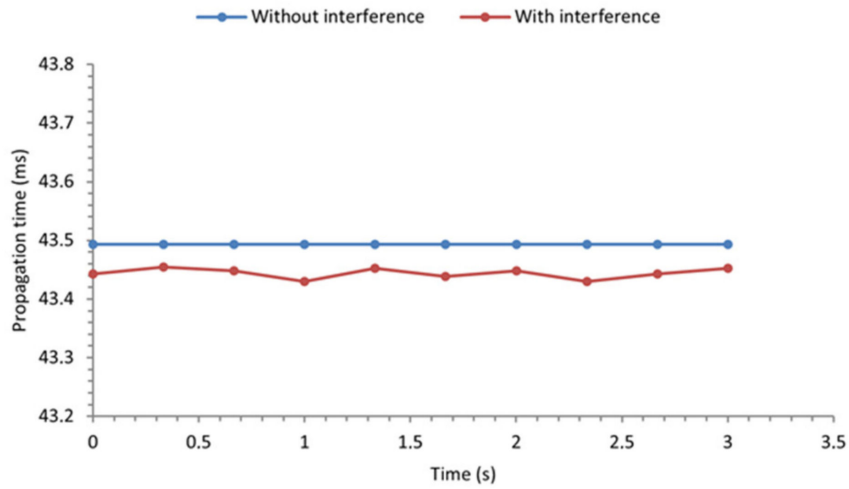

b)

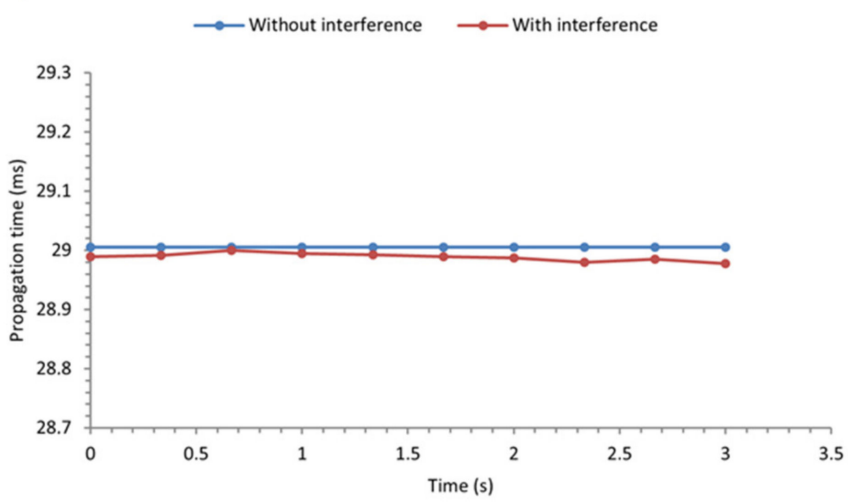

d)

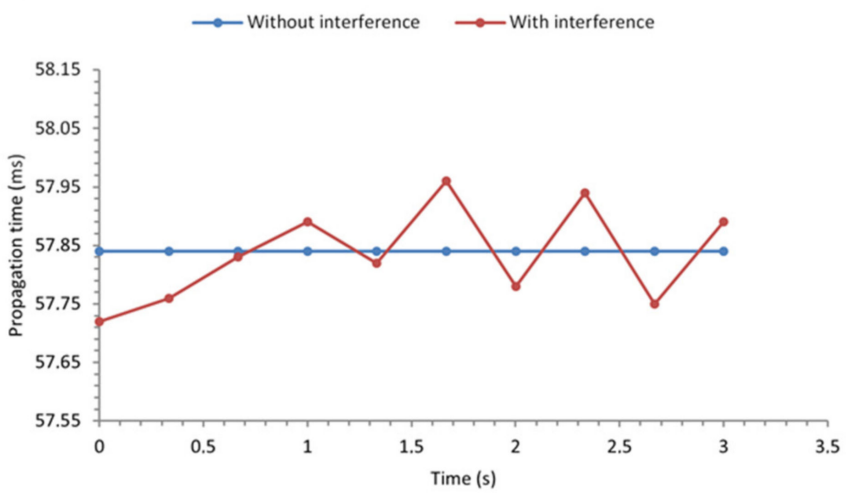

Figure 12. The effect of medium interference on the wave propagation time between AR30 transducers at different distances between the transmitter and receiver: (a) $5 \mathrm{~m}$; (b) $10 \mathrm{~m}$; (c) $15 \mathrm{~m}$; (d) $20 \mathrm{~m}$.

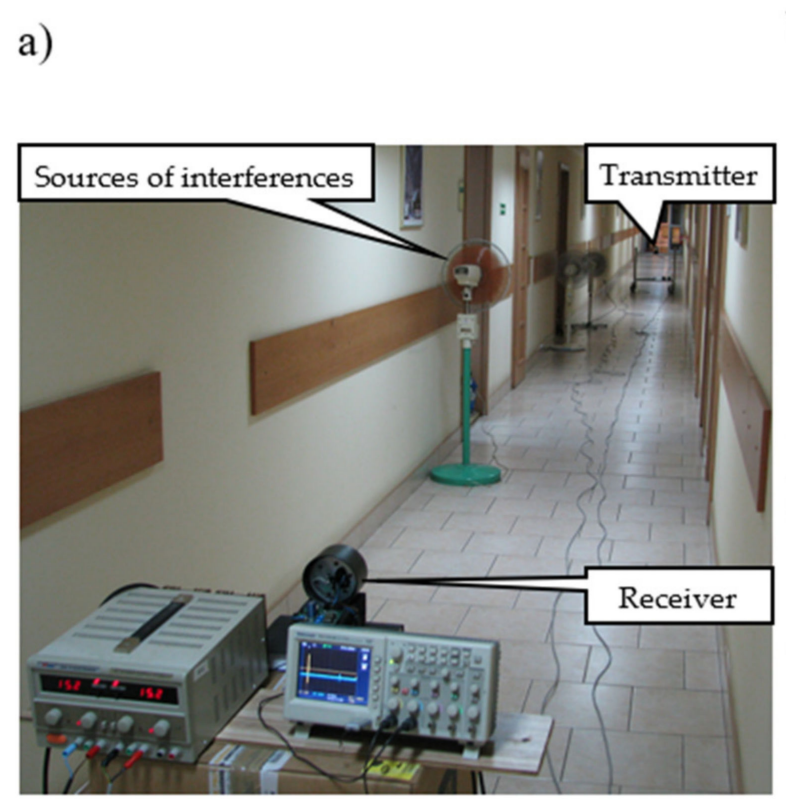

b)
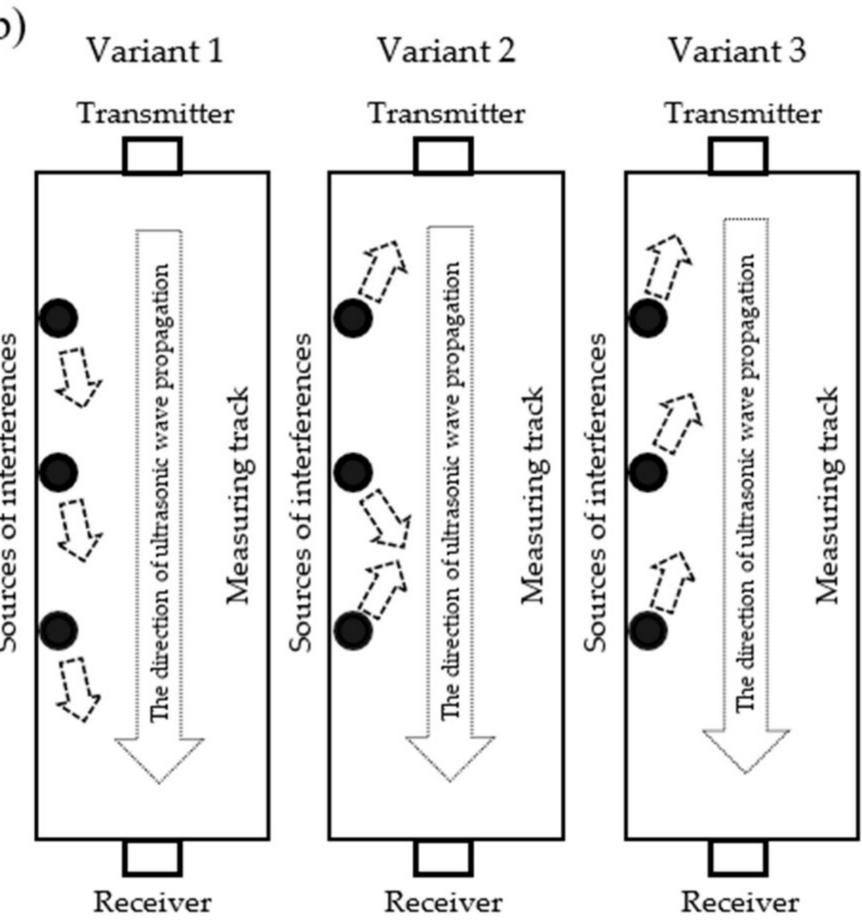

Figure 13. (a) The test setup; (b) variants of arrangement of the interference sources. 
AR30 converters were used in the first series of tests. Figure 14a shows the voltages amplitude recorded in the receiving system, while Figure $14 \mathrm{~b}$ shows the propagation time of ultrasonic waves over a distance of $20 \mathrm{~m}$. The measurements were taken without disturbance of the propagation medium and in the presence of disturbances of the medium uniformity generated by the sources arranged in three different variants.

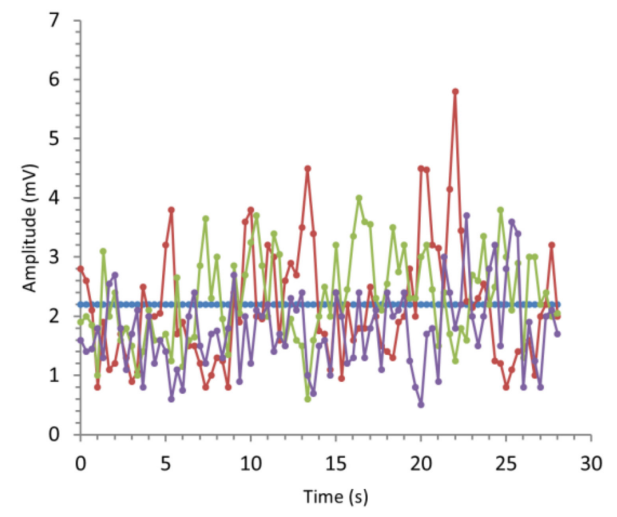

(a)

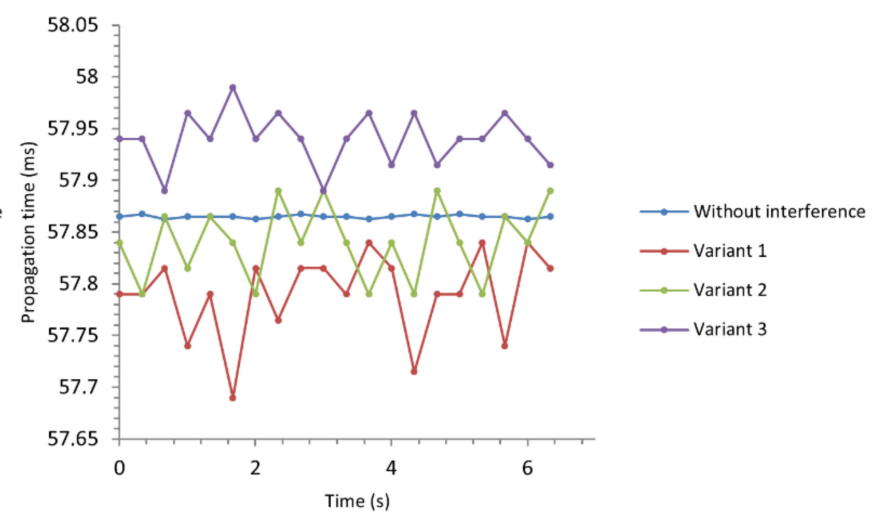

(b)

Figure 14. (a) Voltage amplitudes recorded in the receiver system, with different arrangements of the sources of interference (AR30); (b) Ultrasonic wave propagation time, at distance $20 \mathrm{~m}$ (AR30).

Analogous tests were carried out with the use of AR41 converters; the results are presented in Figure 15a,b.

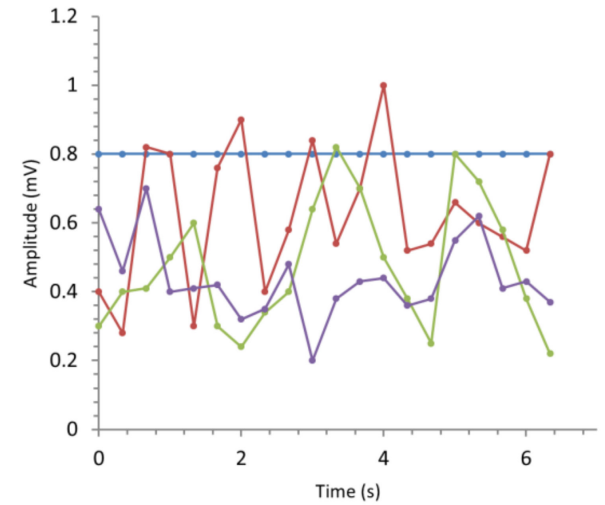

(a)

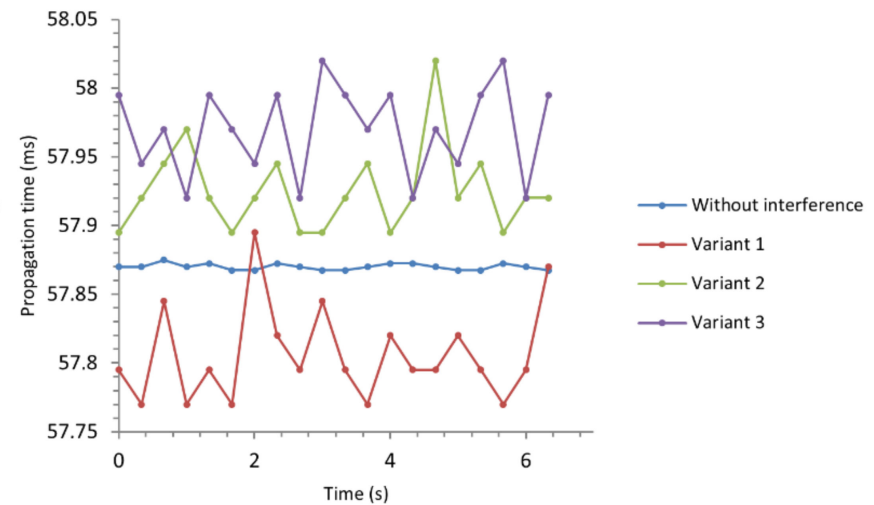

(b)

Figure 15. (a) Voltage amplitudes recorded in the receiver system, with different variants of the sources of interference arrangement (AR41); (b) Ultrasonic wave propagation time, at distance $20 \mathrm{~m}$ (AR30).

The introduction of fans as disturbances to the measurement path has a great influence on the amplitude values of the received signal. In variant 1 , the fans are set in the same direction as the propagated waves, therefore they can temporarily amplify the received amplitude values. This phenomenon is visible both in Figures 14 and 15a.

The impact of disturbances on the measurement results was assessed on the basis of the relative error, determined from the following Equation (7):

$$
\delta=\frac{\mathrm{t}-\mathrm{t}_{\mathrm{z}}}{\mathrm{t}} \cdot 100(\%)
$$

where $\mathrm{t}-$ expected time value (obtained without interferences), $\mathrm{t}_{\mathrm{z}}$-measured time. 
The measured time in the medium without disturbances was assumed as the expected value. Both the amplitude and the propagation time were then constant in time during each series of measurements. The maximum calculated errors are given in Table 2 .

Table 2. Maximum relative errors of measurements.

\begin{tabular}{ccccc}
\hline \multirow{2}{*}{ Fans Arrangement Variant } & \multicolumn{3}{c}{ Maximum Relative Errors of Measurements (\%) } \\
\cline { 2 - 5 } & \multicolumn{2}{c}{ AR30 } & \multicolumn{2}{c}{ AR41 } \\
\cline { 2 - 5 } & Amplitude & Propagation Time & 65 & 0.17 \\
2 & 163 & 0.30 & 73 & 0.26 \\
2 & 82 & 0.13 & 75 & 0.26 \\
\hline
\end{tabular}

It can be stated that disturbances in the homogeneity of the propagation medium (air movements) have a much greater impact on the amplitude of the received signal than on the time of wave propagation. The results indicate that the maximum relative error in the voltage amplitude measurement was $163 \%$, while the maximum error in the propagation time measurement was $0.3 \%$.

In order to more accurately determine how the air movement affects the propagation time, another experiment was carried out. The test setup included AR30 transducers at a $2 \mathrm{~m}$ distance, placed in a strong stream of air generated by fans, air flow was consistent with the wave propagation. The average air flow velocity, measured with an anemometer, was equal to $3 \mathrm{~m} / \mathrm{s}$. Time was measured using an TDS2024B oscilloscope. The propagation time of ultrasonic waves without fan blowing was $t_{\text {norm }}=5.94 \mathrm{~ms}$. Propagation time with forced air movement was $t_{w}=5.884 \mathrm{~ms}$. The difference in these values was $\Delta t=0.056 \mathrm{~ms}$. Assuming the wave propagation speed $340 \mathrm{~m} / \mathrm{s}$, it corresponds to a $0.019 \mathrm{~m}$ distance (absolute error).

Based on the measured time and the known distance $(2 \mathrm{~m})$, the speed of wave propagation was calculated transforming the Equation (2), which was equal to:

- $\quad$ without disturbances (air movement): $336.7 \mathrm{~m} / \mathrm{s}$,

- $\quad$ with forced air movement: $339.9 \mathrm{~m} / \mathrm{s}$.

The difference between these values corresponds almost exactly to the speed of the blower used. Therefore, it can be expected that the measurement errors will depend on the possible movements of the air masses in which the waves propagate. In the situation, when the forecast air flow velocity in coal mine roadway reaches the maximum value of $1 \mathrm{~m} / \mathrm{s}$, propagation time measurement uncertainty up to $0.3 \%$ is expected.

\section{Conclusions}

The initial part of the development of a system for determining the object (e.g., a roadheader) location in the roadway of a hard coal mine presented in this article included, among others, the identification of environmental and legal requirements in the work environment, a definition of the requirements for range and accuracy of the location system, analysis of available technologies and algorithms for determining indoor location, and a review and evaluation of available technologies in terms of meeting the project assumed requirements of the selection of specific devices for testing. The final stage of this part of the work was to conduct a series of tests using the purchased components in the basic configuration to assess whether it would be possible to obtain the assumed parameters of the ready-made system for determining the location. The tests included measurements of distances and other parameters with the use of ultrasonic devices, also taking into account various disturbing factors that may appear under real operating conditions. 
As a result of the analysis of the expected operational conditions, legal constraints, available technologies and algorithms for determining the location, after multi-criteria assessment of the available solutions, it was decided to adopt ultrasound technology for further work, which should ensure sufficient measuring range and accuracy, while at the same time compliance with environmental and legal requirements. Then, the selected ultrasonic devices were tested.

Based on the tests, it can be concluded that the selected ultrasonic transducers (AR30 and AR41) have a sufficient range for the planned applications, working in the transmitterreceiver mode, while the range of the AR30 transducers is greater. Both types of transducers can be used in further work aimed at developing the complete RTLS equipment, enabling the determination of the location of a roadheader operating in harsh environmental conditions in a hard coal mine.

The analysis of theoretical relationships and measurements showed that it is justified to use ultrasonic wave propagation time to determine the distance between the transmitter and receiver, because the disturbances of the propagation environment have a much smaller impact on changing this parameter than on changing the amplitude of the received signal. On the other hand, large fluctuations in the received signal amplitude mean that it is not possible to use additional coding of transmitted ultrasonic waves, because the use of, for example, amplitude modulation, would be subject to a large error. In the future, the research project will test the impact of factors such as temperature, dust and humidity on the uncertainty of measurements using the ultrasound waves, taking into account air flow as a factor affecting the speed of propagation of these waves.

Author Contributions: Conceptualization, S.B., K.S., A.D. and G.K.; methodology, S.B., K.S. and G.K.; validation, G.K. and G.C.; formal analysis, K.S. and A.D.; investigation, S.B. and G.K.; resources, S.B. and A.D.; data curation, S.B., K.S. and G.K.; writing-original draft preparation, S.B. and G.Ć.; writing-review and editing, G.Ć. and S.B.; visualization, S.B. and G.Ć.; supervision, G.K. All authors have read and agreed to the published version of the manuscript.

Funding: This research received no external funding.

Institutional Review Board Statement: Not applicable.

Informed Consent Statement: Not applicable.

Data Availability Statement: The data presented in this study are available on request from the corresponding author.

Conflicts of Interest: The authors declare no conflict of interest.

\section{References}

1. Bhutto, A.W.; Bazmi, A.A.; Zahedi, G. Underground coal gasification: From fundamentals to applications. Prog. Energy Combust. Sci. 2013, 39, 189-214. [CrossRef]

2. Clarke-Hackston, N.; Belz, J.; Henneker, A. Guidance for partial face excavation machines. In Proceedings of the 1st International Conference on Machine Control \& Guidance, Zurich, Switzerland, 24-26 June 2008.

3. Halama, A.; Loska, A.; Szymala, P. Wireless control and directional navigation of a roadheader in drilling process. Pomiary Autom. Robot. 2013, 2, 218-223.

4. ATEX Directive 2014/34/EU. Available online: https:/ / eur-lex.europa.eu/legal-content/EN/TXT/?uri=celex\%3A32014L0034 (accessed on 4 September 2016).

5. Kamel Boulos, M.N.; Berry, G. Real-time locating systems (RTLS) in healthcare: A condensed primer. Int. J. Health Geogr. 2012, 11, 25. [CrossRef] [PubMed]

6. Cwikla, G.; Grabowik, C.; Kalinowski, K.; Paprocka, I.; Banas, W. The initial considerations and tests on the use of real time locating system in manufacturing processes improvement. IOP Conf. Ser. Mater. Sci. Eng. 2018, 400, 042013. [CrossRef]

7. Deak, G.; Curran, K.; Condell, J. A Survey of active and passive indoor localisation systems. Comput. Commun. 2012, 35, 1939-1954. [CrossRef]

8. Thiesse, F.; Fleisch, E. On the value of location information to lot scheduling in complex manufacturing processes. Int. J. Prod. Econ. 2008, 112, 532-547. [CrossRef]

9. Joshi, G.; Nam, S.; Kim, S. Cognitive radio wireless sensor networks: Applications, challenges and research trends. Sensors 2013, 13, 11196-11228. [CrossRef] [PubMed] 
10. Wu, H.; Marshall, A.; Yu, W. Path planning and following algorithms in an indoor navigation model for visually impaired. Proccedings of the Second International Conference on Internet Monitoring and Protection (ICIMP 2007), San Jose, CA, USA, 1-5 July 2007; p. 38. [CrossRef]

11. Borenstein, J.; Everett, H.R.; Feng, L. Where Am I-Systems and Methods for Mobile Robot. Positioning; The University of Michigan: Ann Arbor, MI, USA, 1996.

12. Sobczyk, E.J. Identyfikacja Parametrów wpływających na efektywność drążenia wyrobisk korytarzowych w kopalniach węgla kamiennego. Gór. Geoinżynieria 2010, 34, 199-214. (In Polish)

13. Kissel, F.N. Handbook for Dust Control in Mining; U.S. Department Of Health And Human Services: Washington, DC, USA, 2003.

14. Toraño, J.; Torno, S.; Menéndez, M.; Gent, M. Auxiliary ventilation in mining roadways driven with roadheaders: Validated CFD modelling of dust behaviour. Tunn. Undergr. Space Technol. 2011, 26, 201-210. [CrossRef]

15. ISAP. Rozporządzenie Ministra Gospodarki z Dnia 28 Czerwca 2002 r. In W Sprawie Bezpieczeństwa i Higieny Pracy, Prowadzenia Ruchu Oraz Specjalistycznego Zabezpieczenia Przeciwpożarowego w Podziemnych Zakładach Górniczych. (Dz.U.02.139.1169); ISAP: Warsaw, Poland, 2002. (In Polish)

16. Belle, B.; Zyl, F.; Du Plessis, J.J. Summary Report on Underground Road Header Environmental Control; CSIR Miningtek: Johannesburg, South Africa, 2002.

17. Honysz, J. Górnictwo; Ślask: Katowice, Poland, 2011. (In Polish)

18. Dong, X.; Karrech, A.; Qi, C.; Elchalakani, M.; Basarir, H. Analytical Solution for Stress Distribution around Deep Lined Pressure Tunnels under the Water Table. Int. J. Rock Mech. Min. Sci. 2019, 123, 104124. [CrossRef]

19. Dong, X.; Karrech, A.; Elchalakani, M.; Qi, C.; Manca, M. 3D Bolted cohesive element for the modelling of bolt-reinforced rough rock-shotcrete interfaces. Comput. Geotech. 2020, 125, 103659. [CrossRef]

20. Dong, X.; Karrech, A.; Qi, C.; Basarir, H.; Elchalakani, M. The critical behaviour of finite thickness lining systems in tunnels. Eur. J. Environ. Civ. Eng. 2020, 1-18. [CrossRef]

21. Mautz, R. Indoor Positioning Technologies; ETH Zurich: Zurich, Germany, 2012. [CrossRef]

22. Sanchez, A.; de Castro, A.; Elvira, S.; Glez-de-Rivera, G.; Garrido, J. Autonomous indoor ultrasonic positioning system based on a low-cost conditioning circuit. Measurement 2012, 45, 276-283. [CrossRef]

23. Grzechca, D.; Ziębiński, A.; Paszek, K.; Hanzel, K.; Giel, A.; Czerny, M.; Becker, A. How accurate can UWB and dead reckoning positioning systems be? Comparison to SLAM using the RPLidar system. Sensors 2020, 20, 3761. [CrossRef] [PubMed]

24. Kolodziej, K.W.; Hjelm, J. Local Positioning Systems: LBS Applications and Services, 1st ed.; CRC Press: Boca Raton, FL, USA, 2006.

25. Pirzada, N.; Nayan, M.Y.; Subhan, F.; Hassan, M.F.; Khan, M.A. Comparative analysis of active and passive indoor localization systems. AASRI Procedia 2013, 5, 92-97. [CrossRef]

26. Kołakowski, J. Radiowe Techniki Lokalizacji Obiektów w Pomieszczeniach. Przegląd Telekomun. Wiad. Telekomun. 2011, 6, 206-213. (In Polish)

27. Şahinoğlu, Z.; Gezici, S.; Güvenç, I. Ultra-Wideband Positioning Systems: Theoretical Limits, Ranging Algorithms, and Protocols; Cambridge University Press: Cambridge, UK, 2008.

28. Laaraiedh, M.; Yu, L.; Avrillon, S.; Uguen, B. Comparison of hybrid localization schemes using RSSI, TOA, and TDOA. In Proceedings of the 11th European Wireless Conference, Vienna, Austria, 27-29 April 2011; pp. 626-630.

29. Schmitz, J.; Mathar, R.; Dorsch, D. Compressed time difference of arrival based emitter localization. In Proceedings of the 3rd International Workshop on Compressed Sensing Theory and its Applications to Radar, Sonar and Remote Sensing, Pisa, Italy, June 2015; pp. 263-267. [CrossRef]

30. Brooker, G.; Bishop, M.; Hennessy, R. Evolution of a suite of smart millimetre wave radar systems for situational awareness and automation in mines. Int. J. Smart Sens. Intell. Syst. 2008, 1, 315-353. [CrossRef]

31. Ultrasonic Level Transmitter SmartScan 25. Available online: https:/ /www.directindustry.com/prod/solid-applied-technologiesltd/product-15188-489596.html (accessed on 14 October 2019).

32. TOPCON. Robotic Total Station System. Available online: https://www.topconpositioning.com/total-station-solutions (accessed on 14 October 2019).

33. Simex. Sitrans LR250. Available online: https://www.simex.pl/pl/katalog/radarowy_pomiar_poziomu/sitrans-lr250 (accessed on 15 October 2019).

34. SICK. Distance Sensors. Available online: https://www.sick.com/gb/en/distance-sensors/c/g132151?q=:Def_Type:Product (accessed on 16 October 2019).

35. SYMEO Absolute Positioning. Available online: https://www.symeo.com/en/ (accessed on 17 October 2019).

36. Grzechca, D.E.; Pelczar, P.; Chruszczyk, L. Analysis of object location accuracy for ibeacon technology based on the RSSI path loss model and fingerprint map. Int. J. Electron. Telecommun. 2016, 62, 371-378. [CrossRef]

37. Gudra, T. Właściwości i Zastosowanie Przetworników Ultradźwiękowych do Pracy w Ośrodkach Gazowych; Oficyna Wydawnicza Politechniki Wrocławskiej: Wrocław, Poland, 2005. (In Polish)

38. Manthey, W.; Kroemer, N.; Magori, V. Ultrasonic transducers and transducer arrays for applications in air. Meas. Sci. Technol. 1992, 3, 249-261. [CrossRef]

39. Dobrucki, A. Przetworniki Elektroakustyczne; Wydawnictwa Naukowo-Techniczne: Warszawa, Poland, 2007. (In Polish) 
40. Sharapov, V.; Sotula, Z.; Kunickaya, L. Piezo-Electric Electro-Acoustic Transducers, 1st ed.; Springer: Cham, Switzerland, 2014. [CrossRef]

41. Kim, K.; Choi, H. High-efficiency high-voltage class F amplifier for high-frequency wireless ultrasound systems. PLoS ONE 2021, 16, e0249034. [CrossRef] [PubMed]

42. Airmar Technology Corporation, Air Transducers. Available online: https:/ / www.airmartechnology.com (accessed on 23 November 2019). 